\title{
Persistent diarrhoea: efficacy of a rice-based diet and role of nutritional status in recovery and nutrient absorption
}

\author{
BY S. K. ROY ${ }^{1}$, S. M. AKRAMUZZAMAN ${ }^{1}$, R. HAIDER ${ }^{1}, M$. KHATUN ${ }^{1}$, \\ M. S. AKBAR ${ }^{2}$ AND R. EECKELS ${ }^{1}$ \\ ${ }^{1}$ International Centre for Diarrhoeal Disease Research, Bangladesh, Mohakhali, Dhaka, Bangladesh \\ ${ }^{2}$ Bangladesh Institute of Child Health, Dhaka Shishu Hospital, Sher-E-Bangla Nagar, Dhaka, \\ Bangladesh
}

(Received 17 August 1992 - Revised 6 January 1993 - Accepted 17 February 1993)

\begin{abstract}
A diet based on rice powder, soya-bean oil, glucose, egg-white and salts was given to twenty-six patients of different nutritional status aged 4-18 months with persistent diarrheoa and twenty-five age-matched controls without diarrhoea. Clinical response was monitored during 1 week of dietary treatment and absorption of macronutrients was estimated during a $72 \mathrm{~h}$ balance study. Twenty-one patients $(81 \%)$ recovered from diarrhoea within $7 \mathrm{~d}$. There were significant relationships between nutritional indices, recovery, and absorption of total energy, fat and $\mathrm{N}$. The absorption of fat, protein and carbohydrate in the better nourished controls without diarrhoea was significantly higher than in patients with persistent diarrhoea with better nutrition or malnutrition. The duration of diarrhoea was significantly longer in lighter patients (weight-for-age $<65 \%$ NCHS (1976) standard), in wasted patients (weight/height < $80 \%$ of NCHS) and those with mid upper arm circumference (MUAC) less than $110 \mathrm{~mm}$. There were negative relationships between the period of recovery and the coefficient of absorption of fat $(P<0 \cdot 001)$, total energy intake $(P<0.01)$ and MUAC $(P<0.05)$. Weight-for-age and MUAC showed most effective discriminative power for absorption of nutrients. However, the coefficients of absorption for carbohydrate were not different for any pair of nutritional groups. Absorption of all nutrients was also correlated negatively with severity of persistent diarrhoea on admission. The results of the present study indicate that a rice-based diet is highly effective in the management of persistent diarrhoea, while malnutrition aggravates nutrient malabsorption, increases duration and severity of diarrhoea and less severely malnourished patients do not absorb nutrients as well as healthy controls. Malnutrition and the initial severity of diarrhoea are significant determinants of clinical prognosis and nutrient absorption in persistent diarrhoea.
\end{abstract}

Persistent diarrhoea: Rice-based diet: Malnutrition: Childhood

Persistent diarrhoea (an episode of acute diarrhoea which continues for more than 2 weeks) is poorly understood with regard to its underlying pathophysiology and its management is still problematical (Roy et al. 1989). Nutritional management with an appropriate diet still remains the cornerstone of successful therapy in comparison with acute diarrhoea. Little is known about the role of enteropathogens which are isolated during routine hospital practice (Roy et al. 1989, 1992). It has been shown that malnourished patients suffer from increased severity (Palmer et al. 1976) and duration in acute diarrhoea (Tomkins, 1981) and have a fourteenfold higher risk of mortality even after their recovery (Roy et al. 1983). Stools from patients with persistent diarrhoea indicate severe malabsorption of nutrients (Roy et al. 1990) which is much higher than that occurring in patients with acute diarrhoea (Molla et al. 1982). Management of persistent diarrhoea has always remained problematical, especially because patients had malnutrition and significant digestive and absorptive derangement. The use of a semi-elemental diet such as comminuted chicken has 
been successful in the management of patients with severe persistent diarrhoea (Larcher et al. 1977), but its cost, preparation and availability in communities with limited resources indicate a requirement for an even simpler and less expensive but efficient diet. The interrelationship between acute diarrhoea and malnutrition has been studied extensively during the last few decades (Scrimshaw et al. 1968; Mata et al. 1977), but it is not known whether the nutritional status of patients with persistent diarrhoea affects nutrient absorption and time taken for recovery or whether the degree of malabsorption differs from that of healthy controls. To understand these interactions, during a $7 \mathrm{~d}$ period of therapy with a rice-based simply-formulated diet, twenty-six patients with persistent diarrhoea and various grades of malnutrition and twenty-five healthy age-matched controls were studied using a $72 \mathrm{~h}$ metabolic balance at the Clinical Research Centre of the International Centre for Diarrhoeal Disease Research, Bangladesh (ICDDR, B).

\section{PATIENTS AND METHODS}

Twenty-six male patients aged 4-18 months who were passing three or more liquid or watery stools daily for more than $14 \mathrm{~d}$ were selected. Exclusion criteria included exclusive breast-feeding below 5 months with no intention to introduce a supplementary diet, presence of acute diarrhoea pathogens such as Vibrio cholerae, Salmonella or Shigella spp., systemic infections and kwashiorkor. Twenty-five age-matched healthy controls who attended the Clinical Research Centre with acute diarrhoea at least 4 months earlier and had no history of diarrhoea within the previous 2 months were selected. The study was approved by the ICDDR, B Ethical Review Committee. Informed consent was obtained from the parents of the children. Initial clinical management included rehydration with intravenous fluid, and measurements every $8 \mathrm{~h}$ of food and fluid intakes, stool, urine and vomitus. Initial laboratory investigations on admission included packed cell volume, total leucocyte count and serum electrolytes. Identification of enteropathogens from stool included $V$. cholerae, Shigella spp., Salmonella spp., enterotoxigenic Escherichia coli, Campylobacter jejuni, and Rotavirus. Anthropometric data on body weight, supine length and mid upper arm circumference (MUAC) were taken by a trained nutritionist on admission and weight was measured daily between 09.00 and 10.00 hours. Measurements were taken to the nearest $1 \mathrm{~g}$ for body weight, $1 \mathrm{~mm}$ for length and $2 \mathrm{~mm}$ for MUAC. Breast-feeding was encouraged and breast-milk intake was estimated by weighing the child before and after breast-feeding. The patients and their controls were given a local inexpensive diet (cost US $\$ 0.30 / 1$ ) which was prepared with rice powder, egg-white, soyabean oil, glucose, salts and water (Table 1). It contained $1.67 \mathrm{MJ} / 1$ with $8 \%$ energy from protein. The ingredients of the diet were collected and measured as required with a balance. The whites of two duck eggs were separated, weighed, and then mixed with rice powder, glucose and soya-bean oil and taken in about 1 litre water and boiled for about $5 \mathrm{~min}$. The final volume was made up with additional water and minerals were added. Feeds were given freely once per hour.

The diet was based on culturally-accepted rice powder usually fed to children in Bangladesh. Soya-bean oil has been given to increase the energy density and lower the viscosity; glucose was added for ready absorption and to prevent hypoglycaemia in malnourished children with diarrhoea and for sweeter taste of the diet; egg albumin was easily digestible and as a reference protein had high net protein utilization (NPU); the total osmolality of the diet was $280 \mathrm{mosmol} / \mathrm{kg}$ which was within the safe osmotic range for the small intestine. The diet contained $(\mathrm{g} / \mathrm{l}): \mathrm{NaCl} 1, \mathrm{KCl} 1$, calcium lactate 1 , to provide these essential nutrients in this milk-free diet designed for malnourished children with persistent diarrhoea.

Patients whose stool consistency improved from liquid to soft within $7 \mathrm{~d}$ of dietary therapy were considered to have recovered from persistent diarrhoea. Those who did not 
Table 1. Composition of rice-based diet $(\mathrm{g} / \mathrm{l})$ and some characteristics

\begin{tabular}{|c|c|c|}
\hline \multicolumn{3}{|c|}{ Osmolality } \\
\hline Rice powder & 30 & - \\
\hline Egg white & 50 & - \\
\hline Soya-bean oil & 20 & - \\
\hline Glucose & 25 & 139 \\
\hline $\mathrm{KCl}$ & 1 & 13 \\
\hline $\mathrm{NaCl}$ & 1 & 17 \\
\hline $\mathrm{MgCl}_{2}$ & 0.5 & 5 \\
\hline $\mathrm{CaCl}_{2}$ & 1 & 9 \\
\hline Water $(\mathrm{ml})$ & 935 & \\
\hline Cooked volume $(\mathrm{ml})$ & 1000 & \\
\hline Energy (MJ) & 1.67 & \\
\hline Total osmolality (mosmol $/ \mathrm{kg}$ ) & & 280 \\
\hline
\end{tabular}

recover within $7 \mathrm{~d}$ were given a comminuted chicken-based diet. To determine nutrient absorption, a $72 \mathrm{~h}$ balance study was carried out with the previously-mentioned diet after a $24 \mathrm{~h}$ pre-balance period following admission. Details of the method of balance study have been described previously (Molla et al. 1982; Roy et al. 1990).

The patients were rehydrated with intravenous 'Dhaka Solution' (mmol/1: $\mathrm{Na}^{+} 133, \mathrm{~K}^{+}$ 13, $\mathrm{Cl}^{-} 98, \mathrm{HCO}_{3}^{-} 48$; Cash et al. 1969). After initial rehydration and observation for $8 \mathrm{~h}$ following admission, a study diet was given ad lib, for a $24 \mathrm{~h}$ pre-balance period, followed by a $72 \mathrm{~h}$ balance study, then the diet was continued for a total of $7 \mathrm{~d}$. Patients who continued to suffer from diarrhoea after $7 \mathrm{~d}$ on the diet were defined as failure cases and were then given a comminuted-chicken diet (Roy et al. 1989; ground chicken meat with glucose, soya-bean oil, salts and water) and antibiotics if indicated. Portions of $72 \mathrm{~h}$ homogenized stools during balance study were analysed for total fat by the Van de Kamer et al. (1949) method, $\mathrm{N}$ by the microKjeldahl method (Henry, 1964) and total energy using an adiabatic bomb calorimeter (Gallenkamp, Loughborough, Leics.). Carbohydrate absorption was calculated by subtracting energy from fat and $\mathrm{N}$ from the total dietary energy. There was a limitation of using the calculation of apparent digestibility instead of direct measurement of carbohydrate. The method was used first for its reproducibility in relation to our previous studies (Molla et al. 1982; Roy et al. 1990) and second because there was no alternative method available to the investigators. The coefficient of nutrient absorption was calculated as:

$$
((\text { intake }- \text { loss }) / \text { intake }) \times 100 .
$$

Stool weights and nutrient intake were expressed as $\mathrm{g} / \mathrm{kg}$ body weight per $\mathrm{d}$ and total energy intake as $\mathrm{kJ} / \mathrm{kg}$ body weight per $\mathrm{d}$. Control children were given the same diet and underwent the same balance studies.

\section{Anthropometric assessment and nutritional classification}

Weight-for-age, weight-for-length and length-for-age were calculated from the measurements taken on admission and expressed as percentage of the median NCHS (1976) standard. MUAC was measured using an insertion tape (TALC; Teaching aid at low cost, St. Albans, Herts.). Patients were classified into upper and lower nutritional groups as following: a cut-off point for weight-for-age was taken at $65 \%$, below which a significantly increased risk of mortality has been reported in similar populations (Roy et al. 1983; Chen et al. 1980). A cut-off point for weight-for-length was taken at $80 \%$ to identify the wasted 
and non-wasted children (Waterlow, 1972). A cut-off point for MUAC was taken at $110 \mathrm{~mm}$ below which a sharp rise in mortality has been reported in Bangladeshi children (Briend et al. 1986). Healthy better-nourished controls had a median weight-for-age of $85 \%$, ranging from 70 to $109 \%$ of the NCHS (1976) standard weight-for-age. The control children had a median weight-for-length of $99 \%$, ranging from 81 to $117 \%$.

\section{Statistical procedure}

For the non-normally-distributed data, comparisons between nutritional groups and controls were done by Mann-Whitney $U$ test. Values were log transformed when distribution was skewed and parametric tests were used. Regression analysis was done to estimate the correlations between variables such as the anthropometric data, stool output, nutrient absorption and recovery period. Multiple-regression analyses were performed in statistical models taking the coefficient of absorption and recovery period as dependent variables. Statistical significance was accepted at a probability level of $P<0.05$

\section{RESULTS}

\section{General characteristics and clinical response of patients}

The patients with persistent diarrhoea were significantly malnourished compared with the healthy controls. The median age of the patients was 8.5 months and their nutritional status based on weight-for-age ranged from $47-90 \%$ of the median NCHS (1976) standard. Their purging rate ranged from 30 to $213 \mathrm{~g} / \mathrm{kg}$ body weight per $\mathrm{d}$ on admission. Pre-hospital duration of diarrhoea ranged from 2 weeks to 2 months. Twenty-one of twenty-six patients recovered $(81 \%)$ within $7 \mathrm{~d}$ of dietary therapy, with a median of $4 \mathrm{~d}$. Among the five failure cases, one developed bronchopneumonia, one developed both bronchopneumonia and septicaemia, one developed urinary tract infection with $E$. coli $\left(2 \times 10^{6}\right)$ while the others did not have any systemic infection. The median stool weight in the first $24 \mathrm{~h}$ of admission was significantly higher $(P<0.01)$ in the 'failure' group. During the $72 \mathrm{~h}$ balance period median stool weights were significantly different $(209 v .727 \mathrm{~g} / \mathrm{kg})$ for the 'improved' and 'failure' groups. A significantly higher $(P<0.001)$ loss of nutrients in stool was also observed among the 'failure' group. $\mathrm{N}$ balance ( $\mathrm{N}$ intake $-(\mathrm{N}$ in stool $+\mathrm{N}$ in urine)) was negative in the 'failure' group whereas it was positive among those who recovered. Five patients who did not respond to rice-based diets were given a comminuted-chicken diet and antibiotics and they all eventually improved in a median of $15 \mathrm{~d}$.

The characteristics of the patients with persistent diarrhoea and those of healthy controls are shown in Table 2. They show that the groups were age-matched and the patients were significantly malnourished compared with their healthy counterparts.

Table 3 shows a comparison between the better-nourished and more malnourished patients with persistent diarrhoea using cut-off points of weight-for-age and MUAC as indices of nutritional status. There was no significant difference in pre-hospital duration of diarrhoea, age and dietary intake of children between these nutritional groups.

Linear relationships between weight-for-age, MUAC, duration of diarrhoea before admission, nutrient absorption, recovery period, energy intake and stool weight are shown in Table 4. MUAC as an indicator of nutritional status was correlated positively with absorption of total energy $(r 0.5, P<0.01)$ and negatively with duration of recovery $(r 0.5$, $P<0 \cdot 01)$. A longer recovery period was also related to reduced absorption of total energy $(r 0.7, P<0.001)$. A higher purging rate on admission was associated with a prolonged recovery period $(P<0.001)$. Pre-hospital duration of diarrhoea did not show any significant relationship with nutritional status $(r-0 \cdot 39)$, recovery $(r 0 \cdot 36)$ or absorption of total energy $(r-0 \cdot 07)$. Anthropometric indices, weight-for-age and MUAC were correlated well $(r 0.77, P<0 \cdot 001)$, as expected. 
Table 2. General characteristics of the patients with persistent diarrhoea and healthy control children on admission

(Median values and ranges)

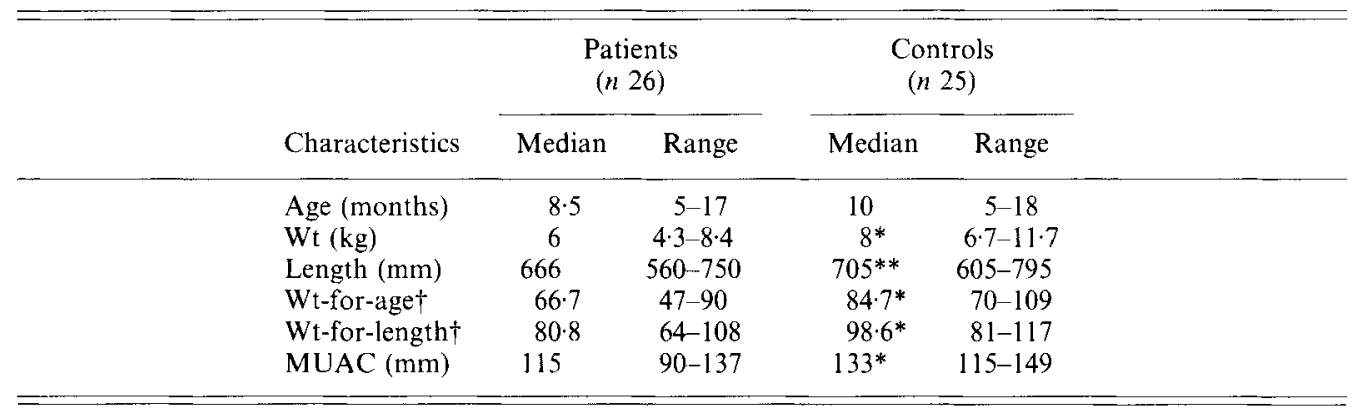

MUAC, mid upper arm circumference.

Median values were significantly different from those of patients with persistent diarrhoea (Mann Whitney $U$ test): ${ }^{*} P=0.001,{ }^{* *} P=0.002$.

$\dagger \%$ of 50 th centile of NCHS (1976).

Table 3. Comparison of admission characteristics between patients with persistent diarrhoea with higher and lower nutritional status*

(Median values and ranges)

\begin{tabular}{|c|c|c|c|c|c|c|c|c|}
\hline \multirow[b]{3}{*}{ Characteristics } & \multicolumn{4}{|c|}{ Wt-for-age $\dagger$} & \multicolumn{4}{|c|}{ MUAC (mm) } \\
\hline & \multicolumn{2}{|c|}{$\begin{array}{l}<65 \% \\
(n 11)\end{array}$} & \multicolumn{2}{|c|}{$\begin{array}{l}>65 \% \\
(n 15)\end{array}$} & \multicolumn{2}{|r|}{$\begin{array}{l}<110 \\
(n 10)\end{array}$} & \multicolumn{2}{|c|}{$\begin{array}{l}>110 \\
(n 16)\end{array}$} \\
\hline & Median & Range & Median & Range & Median & Range & Median & Range \\
\hline $\begin{array}{l}\text { Pre-hospital } \\
\text { duration of } \\
\text { diarrhoea (d) }\end{array}$ & 17 & $14-60$ & 25 & $15-45$ & 22 & $15-60$ & 17 & $14-45$ \\
\hline Age (months) & 9 & $6-13$ & 8 & $5-17$ & 9 & $7-13$ & 8 & $5-17$ \\
\hline $\begin{array}{l}\text { Total energy intake } \\
(\mathrm{kJ} / \mathrm{kg} \text { per } \mathrm{d})\end{array}$ & $447 \cdot 7$ & $301 \cdot 2-594 \cdot 1$ & $376 \cdot 6$ & $230 \cdot 1-648 \cdot 5$ & 4268 & $297 \cdot 1-569 \cdot 0$ & $368 \cdot 2$ & $225 \cdot 9-648 \cdot 5$ \\
\hline $\begin{array}{l}\text { Stool wt lst } 24 \mathrm{~h} \\
(\mathrm{~g} / \mathrm{kg} \text { per } \mathrm{d})\end{array}$ & 136 & $26-330$ & 87 & $25-266$ & 132 & $26-330$ & 78 & $24-203$ \\
\hline $\begin{array}{l}\text { No. of stools/d on } \\
\text { admission }\end{array}$ & 25 & $6-40$ & 9 & $3-35$ & 14 & $5-40$ & 12 & $3-23$ \\
\hline
\end{tabular}

MUAC, mid upper arm circumference.

* For details of patients, see Table 2 and p. 124.

+ Expressed as percentage of the median NCHS (1976) standard.

The values for major independent variables such as MUAC and severity of diarrhoea (stool weight in the first $24 \mathrm{~h}$ ), measures of outcome such as coefficient of absorption of nutrients and period of recovery are shown in Table 5. There is a consistent trend to indicate that children with a higher MUAC had higher coefficients of absorption of nutrients and required fewer days for recovery. Table 5 also shows that almost all the children who failed to recover within $7 \mathrm{~d}$ had a MUAC below $110 \mathrm{~mm}$, their absorption coefficients were much lower and their purging rates were higher. It is also notable that the patients with a higher MUAC had a higher coefficient of absorption and recovered quicker even in cases of initial severe diarrhoea. 
Table 4. Correlations between logs of variables related to prognosis and outcome of treatment with a rice-based diet in patients with persistent diarrhoeat

\begin{tabular}{lccccc}
\hline & LWA & LTOTCAL & LMUAC & LRECOV & LABSCAL \\
\hline LSTVOLD1 & $0 \cdot 35$ & $0 \cdot 46^{* *}$ & -0.41 & $0 \cdot 58^{* * *}$ & $-0 \cdot 75^{* *}$ \\
LWA & - & $-0 \cdot 14$ & $0 \cdot 77^{* *}$ & -0.35 & $0 \cdot 40$ \\
LTOTCAL & - & - & -0.19 & $0 \cdot 48^{* *}$ & -0.28 \\
LDURDR & - & - & -0.39 & 0.36 & -0.07 \\
LMUAC & - & - & - & $-0 \cdot 46^{* *}$ & $0 \cdot 50^{* *}$ \\
LRECOV & - & - & - & - & $-0.69^{* * *}$ \\
$n$ & 26 & - & - & - \\
\hline
\end{tabular}

LSTVOLD1, log of stool weight per $\mathrm{kg}$ body weight in first $24 \mathrm{~h}$; LWA, log of wt-for-age (\% NCHS (1976) median); LTOTCAL, log of total energy intake ( $\mathrm{kJ} / \mathrm{kg}$ per d); LMUAC, log of mid upper arm circumference; LRECOV, $\log$ of recovery period (d); LABSCAL, log of coefficient of absorption of total energy; LDURDR, log of preadmission duration of diarrhoea.

$* * P<0.01, * * * P<0.001$.

$\dagger$ For details of patients, see Table 2 and p. 124.

Table 5. Values for mid upper arm circumference (MUAC), stool weight on first day of admission, coefficient of absorption of total energy and period of recovery for patients with persistent diarrhoea*

\begin{tabular}{|c|c|c|c|c|}
\hline Patient no. & $\begin{array}{c}\text { MUAC } \\
(\mathrm{mm})\end{array}$ & $\begin{array}{l}\text { Stool wt } \\
(\mathrm{g} / \mathrm{kg})\end{array}$ & $\begin{array}{c}\text { Coefficient of } \\
\text { absorption of } \\
\text { total energy }(\%)\end{array}$ & $\begin{array}{l}\text { Recovery } \\
\text { period (d) }\end{array}$ \\
\hline 1 & 115 & 136.4 & $55 \cdot 43$ & 6 \\
\hline 2 & 109 & $236 \cdot 6$ & 28.92 & 22 \\
\hline 3 & 115 & $40 \cdot 0$ & $72 \cdot 59$ & 6 \\
\hline 4 & 117 & $203 \cdot 3$ & $82 \cdot 52$ & 3 \\
\hline 5 & 137 & $55 \cdot 3$ & $62 \cdot 79$ & 9 \\
\hline 6 & 135 & $98 \cdot 1$ & 67.83 & 3 \\
\hline 7 & 134 & $24 \cdot 8$ & $82 \cdot 80$ & 2 \\
\hline 8 & 125 & 87.2 & $80 \cdot 15$ & 7 \\
\hline 9 & 124 & 66.9 & $89 \cdot 83$ & 4 \\
\hline 10 & 105 & 265.9 & $30 \cdot 36$ & 11 \\
\hline 11 & 135 & $26 \cdot 5$ & $92 \cdot 00$ & 2 \\
\hline 12 & 129 & $36 \cdot 3$ & $92 \cdot 03$ & 3 \\
\hline 13 & 125 & $91 \cdot 8$ & 73.49 & 3 \\
\hline 14 & 105 & $100 \cdot 0$ & $54 \cdot 39$ & 6 \\
\hline 15 & 101 & 25.9 & $76 \cdot 83$ & 2 \\
\hline 16 & 106 & $149 \cdot 1$ & $50 \cdot 37$ & 39 \\
\hline 17 & 90 & $46 \cdot 3$ & 73.91 & 7 \\
\hline 18 & 122 & $42 \cdot 1$ & $71 \cdot 15$ & 5 \\
\hline 19 & 116 & $113 \cdot 3$ & $53 \cdot 41$ & 7 \\
\hline 20 & 125 & $69 \cdot 4$ & $89 \cdot 19$ & 2 \\
\hline 21 & 94 & $329 \cdot 5$ & $35 \cdot 92$ & 15 \\
\hline 22 & 109 & $197 \cdot 1$ & $27 \cdot 65$ & 6 \\
\hline 23 & 107 & $115 \cdot 2$ & 49.98 & 6 \\
\hline 24 & 116 & $132 \cdot 2$ & 63.43 & 4 \\
\hline 25 & 115 & 174.8 & 53.57 & 5 \\
\hline 26 & 105 & 101.9 & $68 \cdot 63$ & 3 \\
\hline
\end{tabular}

* For details of patients, see Table 2 and p. 124. 
Table 6. Outcome of dietary therapy according to nutritional status (expressed as \% median NCHS standard and mid upper arm circumference (MUAC)) of the patients with persistent diarrhoea $\dagger^{\dagger}$

(Median values and ranges)

\begin{tabular}{|c|c|c|c|c|c|c|}
\hline \multirow{3}{*}{$\begin{array}{l}\text { Indicator of } \\
\text { nutritional status... }\end{array}$} & \multicolumn{2}{|c|}{ Wt-for-age } & \multicolumn{2}{|c|}{ Wt-for-length } & \multicolumn{2}{|c|}{ MUAC (mm) } \\
\hline & $\leqslant 65 \%$ & $>65 \%$ & $\leqslant 80 \%$ & $>80 \%$ & $\leqslant 110$ & $>110$ \\
\hline & 11 & 15 & 14 & 12 & 10 & 16 \\
\hline $72 \mathrm{~h}$ stool wt $(\mathrm{g} / \mathrm{kg}):$ Median & 479 & $195^{*}$ & 345 & $186^{*}$ & 476 & $202^{*}$ \\
\hline Range & $56-859$ & $50-727$ & $120-859$ & $50-547$ & $56-859$ & $50-547$ \\
\hline Period of recovery (d): Median & 6 & $3^{* * *}$ & 6 & $3 * * *$ & 7 & $4^{*}$ \\
\hline Range & $2-39$ & $2-11$ & $3-39$ & $2-9$ & $2-39$ & $2-9$ \\
\hline Coefficient of absorption (\%) & & & & & & \\
\hline Total energy: Median & 54 & $74^{* * *}$ & 53 & $74 *$ & 50 & $73^{* * *}$ \\
\hline Range & $28-77$ & $30-92$ & $28-90$ & $53-92$ & $28-77$ & $53-92$ \\
\hline Fat: Median & 48 & $71 * * *$ & 51 & $65^{*}$ & 44 & $71 * * *$ \\
\hline Range & $21-97$ & $38-95$ & $21-97$ & $44-95$ & $21-65$ & $44-97$ \\
\hline $\mathrm{N}:$ Median & 48 & $63^{* * *}$ & 53 & 55 & 31 & $60^{* * *}$ \\
\hline Range & $-10-63$ & $-122-82$ & $-10-70$ & $-122-82$ & $-10-63$ & $-122-82$ \\
\hline Carbohydrate: Median & 73 & 85 & 77 & 85 & 64 & 85 \\
\hline Range & $32-97$ & $23-97$ & $23-97$ & $49-94$ & $23-97$ & $55-97$ \\
\hline
\end{tabular}

Mean values for patients with lower nutritional status were significantly different from those who were better nourished for each indicator of nutritional status (Mann-Whitney $\mathbf{U}$ test) : $P<0.05,{ }^{* * *} P<0 \cdot 005$.

$\uparrow$ For details of patients, see Table 2 and p. 124 .

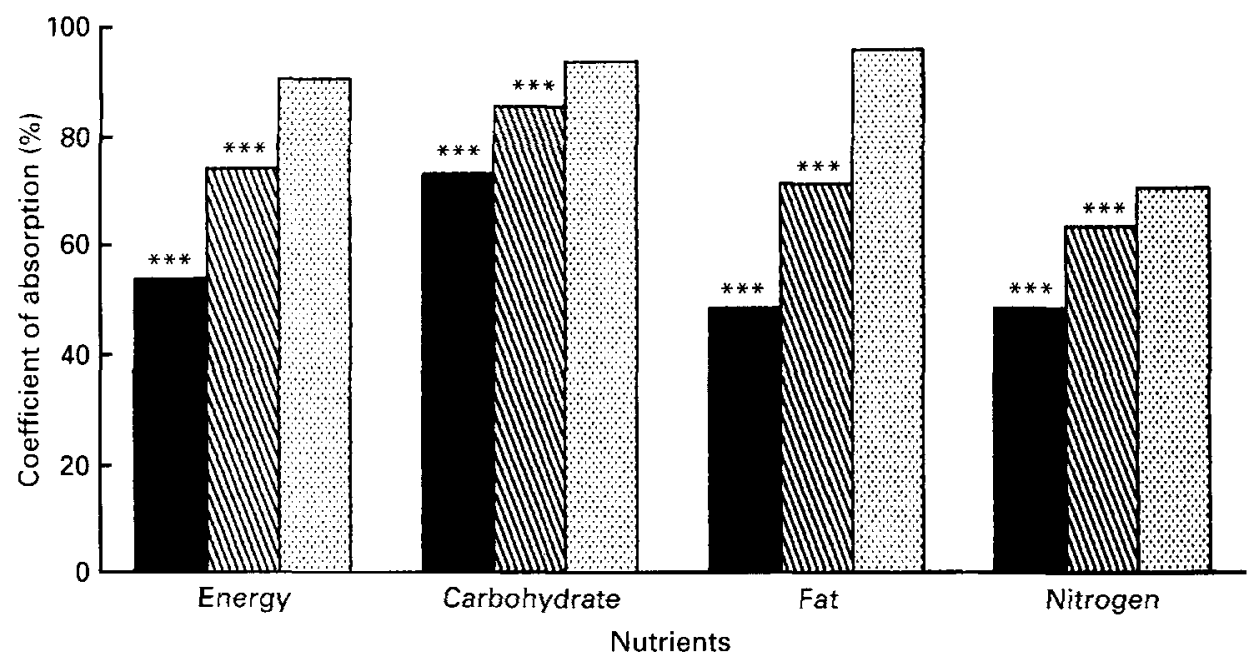

Fig. 1. Coefficients of macronutrient absorption in patients with persistent diarrhoea and in healthy controls. ( $\boldsymbol{(})$, Weight-for-age $<65 \%$ median NCHS (1976) standard; $(\mathbb{8})$, weight-for-age $>65 \%$ median NCHS (1976) standard; (圆), controls. Median values were significantly different from control values: $* * * P<0.001$. For details of subjects, see Table 2 and p. 124.

When nutritional groups based on cut-off points were compared, the difference in clinical outcome became more evident (Table 6). Children having a low weight-for-age $(<65 \%$ of median NCHS (1976) standard) and a low MUAC $(<110 \mathrm{~mm})$ suffered for a significantly longer (twice more) period, lost greater amounts of stools and had significantly reduced absorption of energy, fat and N. Similarly wasted ( $<80 \%$ weight-for-length) patients had 
Table 7. Coefficient of multiple regression taking absorption as a dependent variable for patients with persistent diarrhoea*

(Multiple $R 0 \cdot 85, R^{2} 0 \cdot 72, F 10 \cdot 42$, significant $F 0 \cdot 0000$ )

\begin{tabular}{lrrrr}
\hline \multicolumn{1}{c}{ Variable } & \multicolumn{1}{c}{ S } & Significant \\
\hline TOTCAL (kJ/kg per d) & 0.04 & 0.09 & 0.06 & 0.66 \\
WA (\% NCHS) & -0.48 & 0.37 & -0.21 & 0.27 \\
STFRQD1 (no./d) & -0.79 & 0.39 & -0.38 & 0.05 \\
MUAC (mm) & 5.78 & 2.89 & 0.38 & 0.05 \\
STWTD1 (g) & -0.10 & 0.05 & -0.42 & 0.05 \\
Constant & 43.93 & 26.91 & - & 0.11 \\
\hline
\end{tabular}

TOTCAL, total energy intake; WA, wt-for-age; STFRQD1, stool frequency in day 1 ; MUAC, mid upper arm circumference; STWTDl, stool weight in day 1; B, regression coefficient; SE B, standard error of regression coefficient; Beta, standardized regression coefficient.

* For details of patients, see Table 2 and p. 124.

Table 8. Coefficient of multiple regression with period of recovery as dependent variable for patients with persistent diarrhoea

(Multiple $R 0 \cdot 76, R^{2} 0 \cdot 58, F 7 \cdot 3$, significant $F 0 \cdot 0008$ )

\begin{tabular}{|c|c|c|c|c|}
\hline Variable & B & SE B & Beta & $\begin{array}{c}\text { Significant } \\
T\end{array}$ \\
\hline Log absorption $(\%)^{*}$ & $-1 \cdot 20$ & $0 \cdot 48$ & -0.58 & 0.01 \\
\hline $\log$ MUAC (mm) & -0.83 & $1 \cdot 10$ & $-0 \cdot 12$ & $0 \cdot 45$ \\
\hline Log energy intaket & 0.86 & 0.43 & 0.32 & $0 \cdot 05$ \\
\hline Log stool wt $(\mathrm{g} / \mathrm{kg}$ per $\mathrm{d}) t$ & 0.05 & $0 \cdot 23$ & 0.05 & $0 \cdot 82$ \\
\hline Constant & 2.95 & $3 \cdot 65$ & - & $0 \cdot 19$ \\
\hline
\end{tabular}

B, regression coefficient; SE B, standard error of regression coefficient ; Beta, standardized regression coefficient; MUAC, mid upper arm circumference.

* Coefficient of absorption of total energy.

$\uparrow$ Total energy intake $(\mathrm{kJ} / \mathrm{kg}$ per $\mathrm{d})$.

$\ddagger$ Stool wt per $\mathrm{kg}$ body wt in 1 st $24 \mathrm{~h}$.

a significantly longer recovery period and reduced absorption of energy and fat. It was an important observation that absorption of carbohydrate was not affected in the more malnourished patients.

Fig. 1 shows that the effect of nutritional status was further established when healthy better-nourished controls were compared with malnourished patients. There was a significantly higher absorption (median coefficient) of total energy in healthy controls compared with malnourished patients $(90 v .54 \%, P<0.0001)$ and better-nourished patients (90v. 74\%,P<0.001). There was also a significant difference in carbohydrate absorption between controls and malnourished $(93 v .73 \%, P<0.01)$ and better-nourished patients (93 v. $84 \%, P<0.002$ ). Absorption of both fat and $\mathrm{N}$ were similarly reduced in both nutritional groups of patients with persistent diarrhoea compared with the betternourished controls.

Table 7 shows the coefficients of multiple regression. The nutritional indicator MUAC EGshowed a significant positive relationship with absorption of nutrients $(P<0.05)$ whereas stool weight had a significant negative effect on nutrient absorption $(P<0.05)$. When 
recovery period was taken as a dependent variable, absorption coefficient appeared as a significant determinant $(P<0.01$, Table 8$)$. The interaction between diarrhoea and malnutrition (calculation not shown) was significantly associated with absorption of nutrients (slope $16 \cdot 8$, sE $4 \cdot 2, P<0.0002$ ).

\section{DISCUSSION}

The study showed that twenty-one $(81 \%)$ patients with persistent diarrhoea recovered within 1 week after receiving an inexpensive local diet. Three of five 'failure' patients developed systemic infection. The patients who failed to recover were suffering from more severe malnutrition than those who recovered. It was not known whether systemic infection or nutrient malabsorption was responsible for clinical failure in patients with persistent diarrhoea. The presence of enteropathogens has been reported in patients with prolonged diarrhoea (Gracey \& Stone, 1972; Roy et al. 1992) but their role remains unknown in the present study as the patients with enteropathogens improved without any antibiotics. The rate of purging during the first day of admission and $72 \mathrm{~h}$ balance period correlated negatively with nutritional status. This is consistent with an earlier study of acute diarrhoea where malnourished patients suffered from more severe cholera (Palmer et al. 1976). In our patients, purging rate was positively associated with nutrient malabsorption. Also it has been reported that in patients with persistent diarrhoea a reduction in total gut transit time is associated with reduced absorption (Roy et al. 1992a). The effect of high purging rate on nutrient absorption has not been studied in patients with persistent diarrhoea. The osmotic load caused by the undigested and unabsorbed nutrients might have contributed partly to the high purging rate. Lactose malabsorption is often responsible but the diet was free of lactose. In some of the breast-fed children malabsorption of some of the lactose from their mothers' milk could have occurred. Absorption of energy was correlated positively with MUAC and correlated negatively with the recovery period. It appears that MUAC may serve as an important prognostic factor for absorption of nutrients which may in turn influence the period of recovery from diarrhoea.

In comparison with healthy controls, patients with persistent diarrhoea showed a severe reduction in nutrient absorption and this could have a significant impact on recovery or clinical response. Absorption of nutrients in the more malnourished group of patients with persistent diarrhoea was reduced to half, or even less, of those of healthy controls. The substantial difference in absorption compared with control children was attributed to two factors: (a) persistent diarrhoea, (b) malnutrition; hence, absorption in patients with persistent diarrhoea could be assessed more effectively by comparing children with a similar nutritional status without diarrhoea. However, our patients were suffering from persistent diarrhoea for an average pre-hospital duration of 3 weeks associated with malabsorption of nutrients; moreover, they might have been restricted to reduced food intake during illness. Therefore, it is difficult to separate the effect of persistent diarrhoea from that of malnutrition. It has been shown that the malnourished children suffer from a twofold higher risk of persistent diarrhoea (Bhandari et al. 1989); similarly, severe nutrient malabsorption may aggravate malnutrition in persistent diarrhoea (Roy et al. 1990). Of more concern are the patients with severe malnutrition whose absorption of energy is far below the requirement for maintenance of body weight. Every day with diarrhoea results in an increased cost of sustenance derived from the very poor mass of the malnourished body; hence, wasting is precipitated in such a catabolic event. Moreover, a coefficient of protein absorption of $31 \%$ in more malnourished patients was likely to cause a negative $\mathrm{N}$ balance during persistent diarrhoea. This would increase the deficiency of essential circulatory proteins and somatic proteins and hasten the appearance of oedema leading to 
kwashiorkor. Patients with mucosal injury have a compromised digestive and absorptive capacity which imposes difficulty in efficient feeding for recovery from perisistent diarrhoea and malnutrition. The relationship between nutritional status and nutrient absorption in persistent diarrhoea was further evident when compared with healthy controls.

The duration of recovery and absorption of nutrients were significantly different between the lower and higher nutritional groups. Reduced absorption in malnourished patients could be related to digestive disorders such as insufficient exocrine pancreatic functions (Jain et al. 1986) and brush-border disaccharidase deficiency (Chandra et al. 1968). Absorption of carbohydrate was not affected by poor nutritional status in patients with persistent diarrhoea. It is plausible that digestive enzymes such as salivary amylase, pancreatic amylase and brush-border maltase $(E C 3.2 .1 .20)$ were relatively less affected in malnutrition (Jain et al. 1986). An earlier study from this centre showed that carbohydrate absorption, also, is not reduced during acute diarrhoea, but malnourished patients were not included in that study (Molla et al. 1982).

The wasted children with persistent diarrhoea had significantly lower absorption of fat which reflected a greater reduction in lipase (EC 3.1.1.3) activity in the malnourished children (Jain et al. 1986). The apparent absence of difference in $\mathrm{N}$ absorption between the wasted and non-wasted patients might be related to the presence of excess endogenous $\mathrm{N}$ in stool, enough to mask the actual difference related to dietary $\mathrm{N}$. Although intolerance to cow's milk and soya-bean protein (Whittington et al. 1977) has been reported in patients with perisistent diarrhoea, hypersensitivity to egg protein, a component of our rice-based diet, has neither been reported to be a major problem in such patients nor was it observed in our previous studies (Roy et al. 1990, 1991) or in the present study. Moreover, the increase in intestinal permeability was associated with entry of dietary protein antigens only in premature infants (Jackson et al. 1983). In our patients egg albumin could be a source of antigen but clinical signs of hypersensitivity were absent during the whole study period. Since egg albumin is a reference protein, NPU has been maximum from this source. The use of egg protein is more convenient, in terms of both availability and cost, compared with chicken meat or fish in Bangladesh where food preservation by refrigeration is unavailable to the majority of the population. The use of mung beans (Phaseolus aureus) or lentils (Lens esculenta) as protein sources in diets of patients with persistent diarrhoea in India has been reported (Bhave et al. 1983), but its cost is high in Bangladesh and its success was unremarkable in our younger group of patients. A recent report has suggested that patients with persistent diarrhoea associated with mucosal injury have significantly better repair with Zn supplementation (S. K. Roy, A. Tomkins, R. Haider, R. Behrens, S. M. Akramuzzaman \& D. Mahalanabis, unpublished results). Among other micronutrients, folate and vitamin A are potentially useful in promoting repair and growth of mucosa which might have been inadequate in such malnourished patients suffering from persistent diarrhoea. The wasted patients also had a significantly longer duration of recovery which appeared to be dependent on nutritional status (MUAC), nutrient intake and nutrient absorption.

In conclusion, patients with persistent diarrhoea who were malnourished or had severe diarrhoea on admission had a poorer prognosis during dietary management. In addition to the success of a locally-prepared inexpensive diet, our study suggests that malnourished patients lose about $50 \%$ of nutrients, require twice the time period for recovery and the severity of diarrhoea was about threefold higher. We confirmed that malnutrition in patients with persistent diarrhoea carries a significantly higher risk and should be given higher priority for efficient dietary management. Further in-depth studies are required to identify specific risk factors for macronutrient malabsorption in children with malnutrition with persistent diarrhoea. 
This study was supported by the Project Development Fund of USAID grant to the Director of ICDDR, B. The ICDDR, B is supported by countries and international agencies which share its concern for the health problems of developing countries. Current donors include: the aid agencies of the Governments of Australia, Bangladesh, Belgium, Canada, Denmark, France, Japan, the Netherlands, Norway, Sweden, Switzerland, the United Kingdom and the United States; international organizations include the United Nations Capital Development Fund, the United Nations Development Programme, the United Nations Children's Fund and the World Health Organization; and private foundations include the Ford Foundation and the Sasakawa Foundation. The authors are grateful to Dr D. Mahalanabis for reviewing this manuscript and Mrs N. Majid and staff of the metabolic research ward of ICDDR, B for their help. They also acknowledge the secretarial help of Mr K. M. Rafique.

\section{REFERENCES}

Bhandari, N., Bhan, M. K., Sazawal, S., Clemens, J. D., Bhat Nagar, S. \& Khossoo, V. (1989). Association of antecedent malnutrition with persistent diarrhoea : a case control study. British Medical Journal 298, $1284-1287$.

Bhave, S. A., Pandit, A. N. \& Agarkhedker, S. R. (1983). Protracted diarrhoea and its management. Indian Journal of Pediatrics 20, 173-178.

Briend, A., Dykewicz, C., Graven, K., Mazumder, R. N., Wojtyniak, B. \& Bennish, M. (1986). Usefulness of nutritional indices and classifications in predicting death of malnourished children. British Medical Journal 293, 373-375.

Cash, R. A., Toha, K. M. M., Nalin, D. R., Huq, Z. \& Phillips R. A. (1969). Acetate in the correction of acidosis secondary to diarrhoea. Lancet ii, 302-304.

Chandra, R. K., Pawa, R. R. \& Ghai, O. P. (1968). Sugar intolerance in malnourished infant and children. British Medical Journal 4, 611-613.

Chen, L. C., Chowdhury, A. K. M. A. \& Huffman, S. L. (1980). Anthropometric assessment of energy protein malnutrition and subsequent risk of mortality among pre-school aged children. American Journal of Clinical Nutrition 33, 1836-1845.

Gracey, M. \& Stone, D. E. (1972). Small intestinal microflora in Australian aboriginal children with chronic diarrhoea. Australian and New Zealand Journal of Medicine 3, 315-318.

Henry, R. J. (1964). Clinical Chemistry Principles and Techniques. New York: Harper and Row.

Jackson, D., Walker-Smith, J. A. \& Philip, A. D. (1983). Macromolecular absorption by histologically normal and abnormal small intestinal mucosa in childhood: an in vitro study using organ culture. Journal of Paediatric Gastroenterology and Nutrition 23, 235-247.

Jain, M. K., Bhui, P. S., Mehta, N. J., Taskar, S. P., Sane, S. Y. \& Mehta, A. P. (1986). Pancreatic function in malnourished children. In Diarrhoea and Malnutrition in Childhood, pp. 142-146. [J. A. Walker-Smith and A. S. McNeish, editors]. London: Butterworths.

Larcher, V. F., Shepard, R., Francis, D. E. M. \& Harries, J. T. (1977). Protracted diarrhoea in infancy: analysis of 82 cases with particular reference to diagnosis and management. Archives of Disease in Childhood $\mathbf{5 2}$, 597-605.

Mata, L. J., Kronmal, R. A., Urrutia, J. J. \& Gracia, B. (1977). Effect of infection on food intake and the nutritional status. Perspectives as viewed from the village. American Journal of Clinical Nutrition 30, $1215-1277$.

Molla, A., Molla, A. M., Rahim, A., Sarker, S. A., Mozaffar, Z. \& Rahman, M. (1982). Intake and absorption of nutrients in children of cholera and rota virus infection during acute diarrhoea and after recovery. Nutrition Research 2, 233-242.

NCHS (1976). Growth Charts. Health Resources Administration Publication. HRA 76-1120,25,3. Rockville Pike, Md.: United States Public Health Service.

Palmer, D. L., Koster, F. T., Alam, A. K. M. J. \& Islam, M. R. (1976). Nutritional status: A determinant of the severity of diarrhoea in patients with cholera. Journal of Infectious Diseases 134, 8-14.

Roy, S. K., Akramuzzaman, S. M. \& Akbar, M. S. (1991). Persistent diarrhoea: Total gut transit time and its relationship with nutrient absorption and clinical response. Journal of Pediatric Gastroenterology and Nutrition 13, $409-414$.

Roy, S. K., Alam, A. N., Majid, N., Khan, A. M., Hamadani, J. \& Shome, G. P. (1989). Persistent diarrhoea: A preliminary report on clinical features and dietary therapy in Bangladeshi children. Journal of Tropical Pediatrics 35, 55-59.

Roy, S. K., Behrens, R. H., Haider, R., Akramuzzaman, S. M., Mahalanabis, D., Wahed, M. A. \& Tomkins, A. M. (1992). Impact of zinc supplementation on intestinal permeability in children with acute and persistent diarrhoea. Journal of Paediatric Gastroenterology and Nutrition 15, 289-296.

Roy, S. K., Chowdhury, A. K. M. A. \& Rahaman, M. M. (1983). Excess mortality among children discharged from hospital after treatment for diarrhoea in rural Bangladesh. British Medical Journal 287, 1097-1099. 
Roy, S. K., Haider, R., Akbar, M. S., Alam, A. N., Khatun, M. \& Eeckels, R. (1990). Persistent Diarrhea: Clinical efficacy and nutrient absorption with a rice based diet. Archives of Disease in Childhood 65, 294297. Scrimshaw, N. S., Tayler, C. E. \& Gordon, G. E. (1968). Interaction of Nutrition and Infection. World Health Organization Monograph Series no. 57. Geneva: WHO.

Tomkins, A. (1981). Nutritional status and severity of diarrhoea among preschool children in rural Nigeria. Lancet i, 860-864.

Van de Kamer, J. H., TenBokkel Huinik, H. \& Weyers, H. A. (1949). Rapid method of determination of fat in faeces. Journal of Biological Chemistry 177, 347-355.

Waterlow, J. C. (1972). Classification and definition of protein-calorie malnutrition. British Medical Journal 3, 566-569.

Whittington, P. E. \& Gibson, R. (1977). Soy-Protein intolerance, four patients with concomitant cow's milk intolerance. Pediatrics 59, 730-732. 